\title{
PReS-FINAL-2174: The performance of the new slicc criteria for the classification of sle in children
}

\author{
E Sag $^{1^{*}}$, A Ravelli², ED Batu' ${ }^{1}$ A Tartaglione ${ }^{2}$, AS Khalil $^{3}$, S Marks $^{3}$, S Ozen $^{4}$ \\ From 20th Pediatric Rheumatology European Society (PReS) Congress \\ Ljubljana, Slovenia. 25-29 September 2013
}

\section{Introduction}

The Systemic Lupus International Collaborating Clinics (SLICC) have recently suggested a new set of criteria for the classification of SLE. However the differences between sensitivity and specificities of the ACR criteria and the new SLICC criteria among pediatric SLE patients have not been investigated yet.

\section{Objectives}

We aimed to compare the sensitivity and specificities of the ACR criteria and the new SLICC criteria among pediatric SLE patients.

\section{Methods}

Three main lupus centers from Europe were included in this study. One of these centers was mainly a pediatric nephrology center from UK whereas one was a pediatric rheumatology center from Italy and the last one was a joint one from Turkey. Features present at onset in childhood-onset SLE (cSLE) patients, diagnosed and followed by these three departments between January 2000 to December 2012 were retrospectively analyzed. For the specificity analysis, patients admitted to the respective departments, in whom ANA was deemed necessary by the caring physician in the diagnostic work-up were included as controls. PASW 18,0 for Windows was used for statistical analysis.

\section{Results}

Both criteria were analyzed in 154 cSLE patients with a mean age at disease onset of 12,7 years and 95 controls with a mean age of 8,6 years. In the overall group, the sensitivity and specificity of the ACR criteria were $76,6 \%$ and $91,6 \%$ respectively and that of the SLICC criteria were

\footnotetext{
'Department of Pediatrics, Hacettepe University Faculty of Medicine, Ankara, Turkey

Full list of author information is available at the end of the article
}

$98,7 \%$ and $82,1 \%$ respectively. Four hemolytic uremic syndrome (HUS) patients and four juvenile dermatomyositis (JDM) patients met the SLICC criteria whereas 22 lupus nephritis fell to meet the ACR criteria.

Between the three centers there were marked differences among certain clinical features. On the other hand when we compared our results with the reported prevalances of the criteria in adults, renal involvement, neurologic findings, hemolytic anemia, positive titers for ANA and antidsDNA were more frequent among children whereas chronic skin lesions were less $(\mathrm{p}<0,005)$.

\section{Conclusion}

In this pediatric cohort SLICC criteria performed better, was more sensitive $(p<0,001)$, had fewer misclassifications, however was less specific ( $\mathrm{p}=0,016)$. The specificity of the SLICC criteria was jeopardized with the HUS and JDM cases. The prevalance of certain criteria were significantly different between adults and children, this may necessitate further revision in pediatrics.

\section{Disclosure of interest}

None declared.

\section{Authors' details}

'Department of Pediatrics, Hacettepe University Faculty of Medicine, Ankara, Turkey. ${ }^{2}$ Department of Pediatric Rheumatology, University of Genova, Genova, Italy. ${ }^{3}$ Pediatric Nephrology, Great Ormond Street Hospital, London, UK. ${ }^{4}$ Department of Pediatric Rheumatology, Hacettepe University Faculty of Medicine, Ankara, Turkey.

Published: 5 December 2013

doi:10.1186/1546-0096-11-S2-09

Cite this article as: Sag et al.: PReS-FINAL-2174: The performance of the new slicc criteria for the classification of sle in children. Pediatric Rheumatology 2013 11(Suppl 2):09.
C Biomed Central (c) 2013 Sag et al.; licensee BioMed Central Ltd. This is an Open Access article distributed under the terms of the Creative Commons Attribution License (http://creativecommons.org/licenses/by/2.0), which permits unrestricted use, distribution, and reproduction in any medium, provided the original work is properly cited. The Creative Commons Public Domain Dedication waiver (http://creativecommons.org/publicdomain/zero/1.0/) applies to the data made available in this article, unless otherwise stated. 